\title{
Prevalence of Red Blood Cell Alloantibodies in Pregnant Women and Hemolytic Disease of Newborn in a Tertiary Care Hospital
}

\author{
Pilar Solves*, Inés Gómez-Seguí, Marta Guinot, Ana Saus, Julieta Osorio, Fernanda Martinez, \\ Alfredo Perales, Miguel Ángel Sanz, Nelly Carpio
}

Blood Bank, Hospital Universitari I Politècnic La Fe, Avda Abril Martorell, Valencia 46026, Spain

*Corresponding Author: Pilar Solves, Blood Bank, Hospital Universitari I Politècnic La Fe, Avda Abril

Martorell, Valencia 46026, Spain.Email: solves_pil@gva.es

\begin{abstract}
Background: Hemolytic disease of the newborn is still a matter of concern, due to the morbidity and mortality that can produce in the fetuses and newborns affected. Many different RBC alloantibodies can produce the disease, being anti-D the most frequently implicated followed by anti-c, anti-K and anti-E. Our objective was to analyse the prevalence of RBC significant alloantibodies in pregnant women of our area. In addition, follow-up of deliveries and newborns was performed in order to evaluate the hemolytic potential of the different alloantibodies.
\end{abstract}

Materials and methods: We retrospectively reviewed pregnancies that were positive screened for $R B C$ antibodies for a five-year period. Data was collected at la Fe University Hospital in Valencia. Obstetric and immunohematologic data from pregnant women controlled in the Obstetrics Department from January 2011 to January 2016 were reviewed. Follow-up of newborns affected was also collected.

Results: During the study period, 27609 pregnant women $(23215 R h(D)$ positive and $4394 R h(D)$ negative) were controlled in the obstetric service of the hospital. Of these, $176(0.63 \%)$ had some clinically significant $R B C$ alloantibody and 30 women $(0.1 \%)$ had more than 1 alloantibody. The antigens most often found were anti-D for $R h(D)$ negative women, and anti-E for $R h(D)$ positive women. In thirteen patients requiring IUT, the antibody pattern was as follows: 7 patients with anti-D, 4 anti-D combined with anti-C, 1 anti-K, 1 anti-c combined with anti-E. Plasmapheresis was also performed to one patient.

Discussion: Anti-D remains the most frequent antibody in pregnant women and produces the most severe $H D N$ in our area. Since it is the only alloimmunization that can be prevented, an effort to administrate prophylaxis to all RhD negative pregnant women population is mandatory. Plasmapheresis can be useful, as adjuvant treatment in those cases of severe HDN to reduce the alloantibody titer and consequently ITU needs

Keywords: Alloantibody, hemolytic disease of newborn, intrauterine transfusion

\section{INTRODUCTION}

Hemolytic disease of the newborn (HDN) is still a matter of concern, due to the morbidity and mortality that can produce in the fetuses and newborns affected. HDN leads to severe fetal anemia and consequently to increased cardiac output, tissue hypoxia, fetal hydrops and in the most severe cases, in utero death. Many different red blood cell (RBC) alloantibodies can produce the disease, being anti-D the most frequently implicated followed by anti-c, anti-K and anti- $E^{1,2}$.

Overall prevalence of red blood cell alloantibodies in pregnant women ranges

ARC Journal of Gynecology and Obstetrics between $1 \%$ and $2 \%$ as published in different studies of many different developed and developing countries ${ }^{3-5}$. Introduction of routine antenatal and postnatal prophylaxis in $\mathrm{Rh}$ (D) negative women with anti-D immunoglobulin from the $1970 \mathrm{~s}$ dramatically reduced the incidence of anti-D alloimmunization and consequently of HDN. Before the practise of passive administration of anti-D IgG, the risk of immunization was calculated as high as $16 \%$. Postpartum immunoprophylaxis decreased the incidence of post-pregnancy anti-D immunization to $1-2 \%$ and a further reduction in the alloimmunization rate to $0.1 \%$ was 
achieved by introducing routine antenatal prophylaxis ${ }^{7-8}$. However and despite anti-D prophylaxis administration, a variable percentage of $\mathrm{Rh}(\mathrm{D})$ negative pregnant women still sensitizes due to different reasons. In addition, there is no prophylaxis for the other alloantibodies.

Our objective was to analyse the prevalence of RBC significant alloantibodies in pregnant women of our area. In addition, follow-up of deliveries and newborns was performed in order to evaluate the hemolytic potential of the different alloantibodies.

\section{Material AND Methods}

We retrospectively reviewed pregnancies that were positive screened for RBC antibodies for a five-year period. Data was collected at la $\mathrm{Fe}$ University Hospital in Valencia, Valencian Community, Spanish Mediterranean area. AntiD prophylaxis was administered to D negative women at 28 gestation weeks and after delivery if newborn was $\mathrm{D}$ positive. Obstetric and immunohematologic data from pregnant women controlled in the Obstetrics Department from January 2011 to January 2016 were reviewed. $\mathrm{ABO}$ and $\mathrm{Rh}$ status of mothers and newborns, RBC alloantibodies specificity and transfusions including intrauterine transfusions of affected newborns were collected from Blood Bank database. Newborn data was also reviewed from the medical notes and included: gestational age, hemoglobin and bilirrubin levels at birth, cord blood direct antiglbulin test and red blood cell antigen status, and treatment received before and after birth. Not all data were available for each mother or newborn. Women with anti-D as a result of $\mathrm{Rh}$ Immunoglobulin administration were excluded. Only clinically significant RBC alloantibodies were considered.

$\mathrm{ABO}, \mathrm{Rh}$ typing and the Indirect Antiglobulin Test (IAT) were determined in the automated system ORTHO Autovue Innova (Ortho Clinical Diagnostics, England). Sera of patients with positive results were tested for specificity using panels of RBC with known antigens (Ortho Clinical and Diagnostics, Diamed and Makropanel).

$\mathrm{ABO}$ group and DAT were systematically performed in newborns. The DAT was performed on $\mathrm{RBC}$ from ethylenediaminetetra acetic acid samples according to standard methods. RBC eluates were prepared by acid elution (Elu-Kit II, Gamma Biologicals, Houston, TX, USA). Eluates and sera of patients with positive results were tested for specificity using panels of RBC with known antigens (Ortho Clinical and Diagnostics, Diamed and Makropanel).

Computer software (SPSS, version 13, SPSS Inc., Chicago, IL) was used to perform the statistical analysis. Descriptive statistics are presented for variables. Results are expressed as median and range for continuous variables and as numbers with percentages for categorical variables. Categorical variables were compared by means of Chi square test or Fisher exact test.

\section{Results}

During the study period, 27609 pregnant women $(23215 \mathrm{Rh}$ (D) positive and $4394 \mathrm{Rh}$ (D) negative) were controlled in the obstetric service of the hospital. Of these, $176(0.63 \%)$ had some clinically significant RBC alloantibody and 40 women $(22.7 \%)$ had more than 1 alloantibody. Parity median and range of patients with alloantibodies was 2 (1-8). Tables 1 and 2 show the specificity of alloantibodies according to the D status of women. RBC alloantibodies were detected in $1.3 \%$ and $0.5 \%$ of $\mathrm{Rh}(\mathrm{D})$ negative and $\mathrm{Rh}$ (D) positive women, respectively. The antigens most often found were anti-D for $\mathrm{Rh}$ (D) negative women, and anti-E for Rh (D) positive women. Alloantibodies were detected in third trimester in seventy-four cases.

Table1. Antibody specificities in $D$ negative pregnant women

\begin{tabular}{|l|l|}
\hline D- women (n=57) \\
\hline Antibody specificity & N \\
\hline D & 30 \\
\hline D + C & 10 \\
\hline D + E + G & 1 \\
\hline D + G & 1 \\
\hline K & 1 \\
\hline C & 1 \\
\hline C + E + K & 1 \\
\hline E & 4 \\
\hline M & 6 \\
\hline Lub & 1 \\
\hline Kpa & 1 \\
\hline
\end{tabular}


Prevalence of Red Blood Cell Alloantibodies in Pregnant Women and Hemolytic Disease of Newborn in a Tertiary Care Hospital

Table2. Antibody specificities in D positive pregnant women

\begin{tabular}{|c|c|}
\hline \multicolumn{2}{|l|}{ D+ women $(n=119)$} \\
\hline Antibody specificity & $\mathrm{n}$ \\
\hline $\mathrm{C}$ & 18 \\
\hline$c+E$ & 1 \\
\hline$c+$ Fyb & 1 \\
\hline $\mathrm{c}+\mathrm{Cw}$ & 1 \\
\hline $\mathrm{K}$ & 9 \\
\hline $\mathrm{K}+\mathrm{C}+\mathrm{JKb}$ & 1 \\
\hline $\mathrm{K}+\mathrm{Fya}$ & 1 \\
\hline $\mathrm{K}+\mathrm{Kpa}$ & 1 \\
\hline $\mathrm{C}$ & 1 \\
\hline $\mathrm{C}+$ Fya & 1 \\
\hline $\mathrm{E}$ & 25 \\
\hline $\mathrm{E}+\mathrm{K}$ & 1 \\
\hline $\mathrm{E}+\mathrm{Kpa}$ & 1 \\
\hline $\mathrm{E}+\mathrm{Fyb}$ & 1 \\
\hline $\mathrm{E}+\mathrm{JKb}$ & 1 \\
\hline $\mathrm{E}+\mathrm{M}$ & 1 \\
\hline $\mathrm{E}$ & 1 \\
\hline $\mathrm{M}$ & 15 \\
\hline $\mathrm{JKa}$ & 4 \\
\hline $\mathrm{JKa}+\mathrm{M}$ & 1 \\
\hline $\mathrm{JKb}$ & 2 \\
\hline $\mathrm{S}$ & 1 \\
\hline$S$ & 4 \\
\hline
\end{tabular}

\begin{tabular}{|l|l|}
\hline Kpa & 2 \\
\hline $\mathrm{Cw}$ & 20 \\
\hline Lua & 2 \\
\hline Jsb & 1 \\
\hline $\mathrm{N}$ & 1 \\
\hline
\end{tabular}

The percentage of pregnant women who had clinically significant alloantibodies by blood group $\mathrm{O}, \mathrm{A}, \mathrm{B}$ and $\mathrm{AB}$ were $1.6 \%, 1.8 \%, 1.5 \%$ and $3.2 \%$ respectively ( $\mathrm{p}=\mathrm{ns})$.

Of all sensitized women, 128 patients were followed and delivered at our hospital (37 with anti-D and 91 with other antibodies). In 33 cases $(89.1 \%)$ of the 37 women carrying an anti-D, the newborns were D positive and 25 (67.5\%) had a positive DAT and anti-D in eluate. Of 91 patients with alloantibodies different to D, 46 newborns had a positive DAT $(50.5 \%)$, and the alloantibody was detected in eluate in 18 cases that were positive for the antigen.

In thirteen patients requiring intrauterine transfusion (IUT), the antibody pattern was as follows: 7 patients with anti-D, 4 anti-D combined with anti-C, 1 anti-K, 1 anti-c combined with anti-E. Characteristics of patients requiring ITU are showed in table 3.

Table3. Characteristics of patients requiring ITU

\begin{tabular}{|c|c|c|c|c|c|c|c|c|}
\hline \multicolumn{4}{|c|}{ Before delivery } & \multicolumn{5}{|c|}{ Newborn date at delivery } \\
\hline Patient & $\begin{array}{l}\text { Antibody } \\
\text { (titer) }\end{array}$ & $\begin{array}{l}\text { GA*at } \\
1^{\text {st }} \text { ITU }\end{array}$ & $\begin{array}{l}\text { Number } \\
\text { of ITU }\end{array}$ & GA & \multicolumn{2}{|c|}{ Bilirrubin } & Hemoglobin & Treatment \\
\hline 1 & $\mathrm{D}(4096)$ & 26 & 1 & 34 & \multicolumn{2}{|l|}{ na } & na & na \\
\hline 2 & $\mathrm{D}(16384)$ & 29 & 2 & 33 & \multicolumn{2}{|l|}{9.53} & 9.8 & $\begin{array}{l}\text { Phototherapy+ transfusion } \\
\text { (1) }\end{array}$ \\
\hline 3 & $\mathrm{D}(128)$ & 33 & 1 & 33 & \multicolumn{2}{|c|}{10.25} & 4.3 & $\begin{array}{l}\text { Exchange transfusion }(1)+ \\
\text { transfusion }\left(1 \mathrm{~A}^{* *}\right)\end{array}$ \\
\hline 4 & $\mathrm{D}(4096)$ & 24 & 3 & 32 & \multicolumn{2}{|l|}{ na } & na & na \\
\hline 5 & $\mathrm{D}(2048)$ & 31 & 1 & 32 & \multicolumn{2}{|l|}{3} & 4.1 & $\begin{array}{l}\text { Phototherapy + tranfusion } \\
\text { (3A) }\end{array}$ \\
\hline 6 & $\mathrm{D}(128)$ & 33 & 1 & \multicolumn{5}{|c|}{ Born in another hospital } \\
\hline 7 & $\mathrm{D}(2048)$ & 32 & 1 & \multicolumn{2}{|l|}{33} & 2.55 & 10.9 & $\begin{array}{l}\text { Phototherapy+ transfusion } \\
(2 \mathrm{~A})\end{array}$ \\
\hline 8 & $\begin{array}{l}\mathrm{D}+\mathrm{C} \\
(2048 / 16)\end{array}$ & 30 & 1 & \multicolumn{2}{|l|}{30} & 9.47 & 15.4 & $\begin{array}{l}\text { Exchange transfusion }(1)+ \\
\text { transfusion }(2 \mathrm{~A})\end{array}$ \\
\hline 9 & $\begin{array}{l}\text { D + C } \\
(16384 / 16)\end{array}$ & 24 & 2 & \multicolumn{2}{|l|}{26} & \multicolumn{3}{|c|}{ Fetal death after $2^{\text {nd }}$ ITU } \\
\hline 10 & $\begin{array}{l}\mathrm{D}+\mathrm{C} \\
(16384 / 8)\end{array}$ & 24 & 6 & \multicolumn{2}{|l|}{31} & 3.92 & 15.3 & $\begin{array}{l}\text { Phototherap +transfusion( } \\
5 \mathrm{~A})\end{array}$ \\
\hline 11 & $\begin{array}{l}D+C \\
(256 / 128)\end{array}$ & 32 & 1 & \multicolumn{2}{|l|}{33} & 9.53 & 8.3 & $\begin{array}{l}\text { Exchange transfusion }(2)+ \\
\text { transfusion }(1 \mathrm{~A})\end{array}$ \\
\hline 12 & K (1024) & 30 & 2 & \multicolumn{2}{|l|}{33} & 5.29 & 11 & Transfusion $(2 \mathrm{~A})$ \\
\hline 13 & $\begin{array}{l}c+E \\
(512 / 2)\end{array}$ & 28 & 1 & \multicolumn{2}{|l|}{29} & 2.62 & 5.5 & $\begin{array}{l}\text { Exchange transfusion }(1) \\
+ \text { transfusion }(5 \mathrm{~A})\end{array}$ \\
\hline
\end{tabular}

*Gestational age. **Aliquot. Na: not available

One fetal death occurred after a second ITU. Plasma exchange was also performed in the patient number 10 in an attempt to reduce the
ITU requirements. Anti-D and anti-C titres ascended to 131072 and 16384 respectively after the fifth ITU. Six procedures were 
performed between 26 and 28 weeks gestation, allowing a reduction of anti-D and anti-C titers to 16384 and 128 respectively. After, a $6^{\text {th }}$ ITU was performed and baby was delivered at 31 gestation week. A healthy newborn was obtained who required transfusion of 5 antigen negative RBC aliquots and phototherapy, being discharged 30 days after. Hemoglobin and bilirubin at birth were $15.3 \mathrm{~g} / \mathrm{dl}$ and $3.92 \mathrm{mg} / \mathrm{dl}$, respectively.

Among patients carrying anti-D who did not require any treatment during pregnancy $(n=26)$, 6 newborns received phototherapy + antigen negative RBC transfusion, 6 were treated with phototherapy, 1 received antigen negative RBC transfusion and 1 received an exchange transfusion after delivery. Overall, 25 patients with anti-D required any treatment during pregnancy or after delivery $(67.5 \%$ of patients with anti-D who delivered at la Fe Hospital). Among 91 patients carrying and alloantibody with specificity different to $\mathrm{D}$ and who did not require treatment during pregnancy, 5 newborns received phototherapy, and 1 received phototherapy + antigen negative $\mathrm{RBC}$ transfusion.

\section{DISCUSSION}

To our knowledge, this is the first study analysing the presence of maternal red blood cell alloantibodies, and their clinical consequences on newborns in our area. The prevalence of $\mathrm{RBC}$ alloantibodies in pregnant women of our hospital is less than $1 \%$, which is low as compared to other reports in which prevalence is systematically higher than $1 \%$, ${ }^{9}$. On the contrary, $\mathrm{Pal}$ et $\mathrm{al}^{10}$ have published a prevalence of maternal red blood cell alloimmunization of $0.73 \%$ in Queensland, Australia, while Zwingerman $\mathrm{R}$ et $\mathrm{al}^{5}$ in an analysis performed in Canadian prenatal population revealed a prevalence of alloimmunization as low as $0.36 \%$. In the last study, cases of anti-K as sole antibody were excluded. In most studies the most frequent antibody detected was anti-E $\mathrm{E}^{3,5,10}$. We should note that in our study, anti-D (23.8\%) was the most frequent alloantibody detected in pregnant women, followed by anti-E (20.4 \%) and anti-M $(13.0 \%)$. Anti-E was the antibody most frequented detected in $\mathrm{Rh}(\mathrm{D})$ positive women. Despite the routine prophylaxis with anti-D immunoglobulin that is well established, anti-D was developed in almost $1 \%$ of $\mathrm{Rh}$ (D) negative pregnant women at our hospital. In fact, anti-D contributed to $23.8 \%$ of total alloimmunizations and is the first cause of severe HDN due to RBC alloantibodies. Of 13 ITU performed during the study period, 11 were due to HDN caused by anti-D. The reasons for persistence of anti-D immunization in pregnant women, is beyond the reach of our study. Besides, our hospital is a tertiary-care facility that receives the high risk patients from other institutions and the alloimmunization data cannot be an accurate reflection of the prevalence in the general pregnant population.

In our study, $17 \%$ of alloimmunized women had a combination of antibodies, being the most frequent association of anti-D + anti-C. These results are different of previous studies in which the combination of antibodies was detected in $27 \%^{11}$ and $13 \%{ }^{12}$. The presence of more than 1 alloantibody has been associated to a higher risk to develop significant of HDN, than those with a single antibody, especially if the anti-D is present ${ }^{11,12}$. In this sense, it has to be noted that in our study $38 \%$ of ITU were performed to women carrying more than 1 alloantibody, suggesting a high risk for these patients.

ITU is an effective and safe treatment that has contributed to perinatal survival rates near or more than $95 \%$ in experienced centres ${ }^{13,14}$. However, treatment of HDN before 20 weeks gestation with ITU is a technical challenge because of the difficulty to gain the fetal vascular access. A combination of plasmapheresis and intravenous immunoglobulin has been reported in the literature for treatment of HDN in first trimester high-risk pregnancies ${ }^{15,}{ }^{17}$. In these reports, plasmapheresis was used in addition to the IG with the aim of reducing the start of fetal anemia, and consequently the ITU requirements. Other authors ${ }^{18}$ have used plasmapheresis alone for the same purpose. We also initiated plasmapheresis to the case number 10 of the table 3, in order to decrease the alloantibody titers and consequently the ITU needs. Our case has some differences when compared to other cases of anti-D treated with plasma exchange: the procedure was initiated late in 26 gestation week, after detecting an important increase in alloantibody titers and when the patient had received 5 ITUs. However we thought that fetus could benefit of this procedure by reducing the maternal alloantibody titters. In fact, after 6 procedures, a significant reduction of antibodies was achieved. Newborn outcome was good. We have only found 1 similar case in the literature, 
in which the antibody implicated was anti- $\mathrm{K}^{18}$. A combination of ITU and plasmapheresis was employed from 27 gestation week's with good newborn outcome.

In conclusion, anti-D remains the most frequent antibody in pregnant women and produces the most severe HDN in our area. Since it is the only alloimmunization that can be prevented, an effort to administrate prophylaxis to all $\mathrm{RhD}$ negative pregnant women population is mandatory. Plasmapheresis can be useful, as adjuvant treatment in those cases of severe HDN to reduce the alloantibody titer and consequently ITU needs.

\section{REFERENCES}

[1] Murray NA, Roberts IA. Haemolytic disease of the newborn. Arch Dis Child Fetal Neonatal Ed 2007; 92:F83-88.

[2] Moise KJ, Argoti PS. Management and prevention of red cell alloimmunization in pregnancy. Obstet Gynecol 2012; 120:11321139.

[3] Smith HM, Shirey RS, Thoman SK, et al. Prevalence of clinically significant red blood cell alloantibodies in pregnant women at a large tertiary-care facility. Immunohematology 2013 ; 29:127-130

[4] Karim F, Moiz B, Kamran N. Risk of maternal alloimmunization in southern Pakistan. A study in a cohort of 1000 pregnant women. Transfus Apher Sci 2015; 52(1):99-102.

[5] Zwingerman R, Jain V, Hannon J, et al. Alloimmune red blood cell antibodies: Prevalence and pathogenicity in a Canadian prenatal population. J Obstet Gynaecol Can 2015; 37(9):784-790.

[6] 6. Bowman JM. Controversies in $\mathrm{Rh}$ prophylaxis. Who needs $\mathrm{Rh}$ immune globulin and when should it be given?. Am J Obstet Gynecol 1985; 151:289.

[7] Bowman JM. The prevention of Rh immunization. Transfus Med Rev 1988; 2:129.

[8] Qureshi H, Massey E, Kirwan D, et al. BCSH guideline for the use of anti-D immunoglobulin for the prevention of haemolytic disease of the fetus and newborn. Transfusion medicine 2014; 24:8-20
[9] Altuntas N, Yenicesu I, Himmetoglu O, et al. The risk assessment study for haemolytic disease of the fetus and newborn in a university hospital in Turkey. Transfus Apher Sci 2013; 377-380.

[10] Pal M, Williams B. Prevalence of maternal red cell alloimmunization: a population study from Queensland, Australia. Pathology 2015; 47(2): 151-155.

[11] Nordwall M, Dziegiel M, Hegaard HK, et al. Red blood cell antibodies in pregnancy and their clinical consequences: synergistic effects of multiple specificities. Transfusion 2009; 49:2070-2075.

[12] Markham KB, Rossi KQ, Nagaraja HN, et al. Hemolytic disease of the fetus and newborn due to multiple maternal antibodies. Am J Obstet Gynecol 2015;213:68e1-5.

[13] Birchenal KA, Illanes SE, Lopez F, et al. Neonatal outcomes of pregnancies affected by haemolytic disease of the foetus and newborn and managed with intrauterine transfusion. A service evaluation. Blood Transfus 2013; 11:548-552.

[14] Sainio S, Nupponen I, Kuosmanen M, et al. Diagnosis and treatment of severe haemolytic disease of the fetus and newborn: a 10-year nationwide retrospective study. Acta Obstet Gynecol Scand 2015; 94(4):383-390.

[15] Ruma MS, Moise KL, Kim E, et al. Combined plasmapheresis and intravenous immune globulin for the treatment of severe maternal red cell alloimmunization. Am J Obstet Gynecol 2007; 196:e1-138.e6.

[16] Fernández-Alba JJ, León R, González-Macías $\mathrm{C}$, et al. Treatment of $\mathrm{D}$ alloimmunization in pregnancy with plasmapheresis and intravenous immune globulin: case-report. Transfus Apher Sci 2014;51: 70-72.

[17] Novak DJ, Tyler LN, Reddy RL, et al. Plasmapheresis and intravenous immune globulin for the treatment of D alloimmunization in pregnancy. $\mathrm{J}$ Clin Apher 2008; 13:183-185.

[18] Lakhwani S, Machado P, Pecos P, et al. Kell haemolytic disease of the fetus. Combination treatment with plasmapheresis and intrauterine blood transfusion. Transfus Apher Sci 2011; 45:9-11

Citation: Pilar Solves, Inés Gómez-Seguí, Marta Guinot, Ana Saus, Julieta Osorio, Fernanda Martinez, et al. Prevalence of Red Blood Cell Alloantibodies in Pregnant Women and Hemolytic Disease of Newborn in a Tertiary Care Hospital. ARC Journal of Gynecology and Obstetrics 2017; 2(2):18-22. DOI: dx.doi.org/ 10.20431/2455-9792.0202005

Copyright: (C) 2017 Authors. This is an open-access article distributed under the terms of the Creative Commons Attribution License, which permits unrestricted use, distribution, and reproduction in any medium, provided the original author and source are credited. 